\title{
Experimental Investigation to Determine the Concentration of Radon in Cosmetics Using a Nuclear Track Detector (CR-39)
}

\author{
Osama Mohammed ${ }^{1}$, Ahmed R. Mathloom²*, Alaa A. Shanef ${ }^{3}$ \\ ${ }^{1}$ Technical Institute of Amara, Southern Technical University, Basra 61004, Iraq \\ ${ }^{2}$ Department of Physics, College of Education pure Sciences, University of Thi-Qar, Thi-Qar 64001, Iraq \\ ${ }^{3}$ Ministry of Education, The-Qar General Directorate of Education, Thi-Qar 64001, Iraq
}

Corresponding Author Email: ahmedrasool30.eps@utq.edu.iq

https://doi.org/10.18280/i2m.200308

Received: 13 March 2021

Accepted: 31 May 2021

\section{Keywords:}

radon concentration, cosmetic, radiation, exposure, annual equivalent dose

\begin{abstract}
The nuclear track detector CR-39 is used in the detection of radon gas concentration in selected samples of cosmetics in the local market. Products of wide use are selected and employed in the current study. Six types of cosmetic products of different origins are tested by taking equivalent quantities of these products and putting them in plastic boxes. The detector is left with the samples for a period of 50 days. In addition to measuring the rate of surface evaporation of radon gas, measurements of the annual equivalent dose of radon gas are also carried out. The results show that the highest concentration of radon gas is in Charcoal Facial SCRuB (American origin) and it is equal to $0.0795 \mathrm{~Bq} / \mathrm{m}^{3}$, whereas the lowest one in "bb" cream basis (5 in 1) is equal to $0.0355 \mathrm{~Bq} / \mathrm{m}^{3}$. Based on specific international organizations and agencies, the concentration of radon in the samples under consideration is within the acceptable limits.
\end{abstract}

\section{INTRODUCTION}

Environmental pollution is one of the most important sources of concern for humans because of its multiple forms and its various forms that are expending and affecting the environment in general and human health in particular [1]. The World Health Organization defined pollution as "every quantitative or qualitative change in the components of the globe at the natural limit, whether an increase or decrease that leads to an imbalance in the natural balance of the components of the ecosystem [2].

Pollution with radioactive materials such as uranium, radon and beta particles are an environmental phenomenon that has taken a great deal of interest from researchers. Radon is a radioactive, colorless and odorless gas [3]. It is one of the natural sources of atomic radiation that transforms in the chain of disintegration of uranium-238 and is seven and a half times heavier than air [4]. It is difficult for people to understand the dangers of radon for reasons most of which are related to the nature of this gas and the risks it causes, as it is the absence of direct physical evidence of the presence of radon gas that cannot be seen, does not smell, and cannot be perceived [5]. Living organisms to radiation from two sources, the external environment exhibits internal exposure and external exposure.

The first exposure is exposure to radiation (chronic exposure), the other is exposure to radiation (acute exposure) [6]. Exposure to radiation for prolonged periods of continuous or intermittent exposure and is subject to damage as is the case [7]. As for acute exposure, it is for short periods of time compared to the first type and the radiation doses in which the lens of the eye appears, temporary or permanent sterility and genetic mutations as well as types of cancers, and that the injury to the body's organs depends on the amount of radiation doses that the organ was exposed to, the reading appears after exposure to the jump to a short time [8]. Many people use cosmetics, either to give attractiveness to the face or to conceal some of the defects that the skin may suffer from. Therefore, it is considered as a quickest way to get rid of these defects. On the other hand, that cosmetics have hazards that far outweigh their advantages [9]. There are many studies concerned with the detection and calculation of radon concentrations in cosmetics, such as the research performed by Seoud [10] for cosmetics in Kuwait, where radon concentrations have been found to be below allowable limits and do not pose a risk. Salman et al. [11] studied the concentration of radon in cosmetics in Hilla, Iraq, and discovered that it is healthy for human use. Using multiple technologies, Ali et al. [12] studied the background radiation level in Mosul University Campus and reported an empirical equation between the field and the laboratory measurements of the dose rate in air. Reimann et al. [13] analyzed several samples of hard rock groundwater for their radon and fluoride contents and recommended that the findings require urgent assessment. Fiume et al. [14] analyzed and discussed the efficacy of talc for use in cosmetics. Their findings have shown that talc should not be applied to the skin when the epidermal barrier is missing or greatly disrupted. Papadopoulos et al. [15] tested various commercial cosmetic clays which have different color by using X-ray powder diffraction. Milena-Pérez et al. [16] studied the side effects of the plant extracts and raw materials which used for therapeutic and beauty purposes. The results uncovered that no radiological risk derived from the use of these samples.

According to the above survey, several studies have used different products, samples, and techniques identify the side effects of cosmetic use, but there is an urgent need for further studies. Therefore, the aim of this work is to determination of radon concentration in cosmetics, reward and finding the 
surface evaporation rate of radon gas.

\section{MATERIALS AND METHODS}

\subsection{Sample preparation and CR-39 reagent}

Samples are collected from the local market following a survey of the most widely used ones, during which six types of cosmetics are selected. $2.5 \mathrm{~g}$ per sample is weighed using a Japanese-made sensitive scale (HANGPING JA1003). Then, these sample quantities were taken and placed in a plastic box with the measurements shown in the Figure 1. The distance between the sample and the detector has been set and it is equal to the distance between the sample and the detector $(6.3 \mathrm{~cm})$.

The box was securely secured, and a coating of silicone was applied over the box cover to minimize contamination and to ensure that the samples were not contaminated by external sources. CR-39 Reagent consists of a small piece of plastic that is sensitive to the alpha particles released by radon gas and its offspring. It was cut out into small pieces, each of which was $(1 \times 1.5 \mathrm{~cm}$ dimensions $)$ while $(500 \mu \mathrm{m})$ thick, then the same number of pieces of the plastic case and attached to the inner covers at the top of the box with a sticker. After 50 days, samples were left to ensure the alpha particles were captured on the detector as a result of radon dissolution released by the samples. The diameter of the plastic box from the top was $3.9 \mathrm{~cm}$, while the diameter from the bottom was $3.6 \mathrm{~cm}$ and the height was $(6.8 \mathrm{~cm})$, as shown in Figure 1.

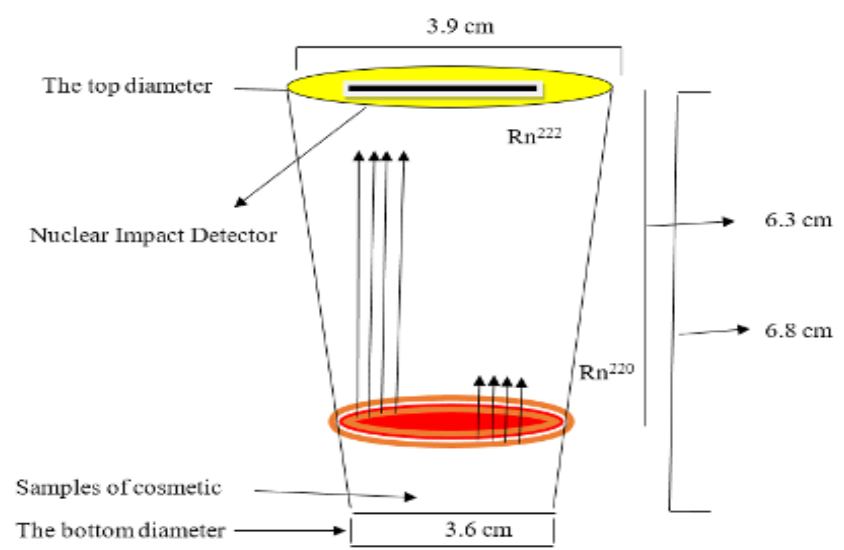

Figure 1. Experimental device

\subsection{Data reduction}

Following expiry of the period of time, the reagents were extracted, and chemical skimming was performed using the abrasive $(\mathrm{NaHO})$ solution with sufficient skimming conditions $(6.25 \mathrm{~N})$ and a temperature of $\left(70^{\circ} \mathrm{C}\right)$ for a five-hour period.

The number of Nave traces formed on the detector and for all samples was calculated by means of an optical microscope with a magnification power of X 400 and as follows:

1. The track density $\rho_{x}$ is considered according to the following equation [17]

$$
\rho_{x}=\frac{N_{\text {ave }}}{A}
$$

where, $\rho_{x}$ : Track density $\left(\frac{\text { tracks }}{m m^{2}}\right)$.
$N_{\text {ave }}:$ Average of total tracks.

$A$ : Area of field view.

2. Then, the concentration of tested samples is determined according to the relationship:

$$
C_{x}=\frac{\rho_{x}}{\text { slope }}
$$

When (slope $=\frac{\rho_{S}}{C_{S}}$ ), determined from Figure 2, for standard models.

where:

$$
\begin{aligned}
C_{x} & =\left(\frac{B q}{c m^{3}}\right) \text { Radon concentration in samples. } \\
C_{s} & =\left(\frac{B q}{c m^{3}}\right) \text { Radon concentration in standard gene. } \\
\rho_{x} & =\left(\frac{t r a c k s}{m m^{2}}\right) \text { Trace density of samples. } \\
\rho_{s} & =\left(\frac{t r a c k s}{m^{2}}\right)
\end{aligned}
$$

3. The rate of radon evaporation of the samples under consideration.

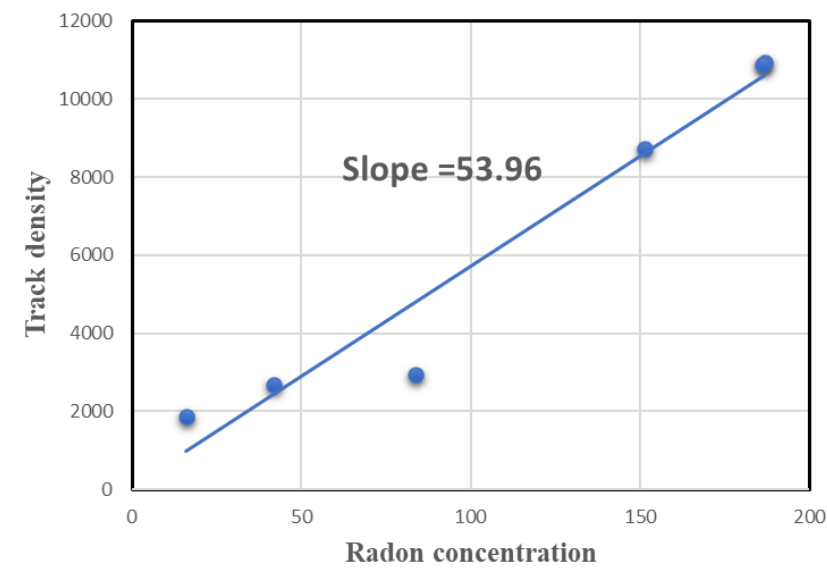

Figure 2. Relationship between radon concentration and trace density for standard models [18]

The surface evaporation rate means the number of atoms of radon gas leaving (or radioactivity) from the surface of the material per unit surface area per unit time (Bq. $\left.\mathrm{M}^{-1} . \mathrm{H}^{-1}\right)$ [12]. It is calculated from the following relationship $[17,18]$ :

$$
E_{\text {exh }}=\frac{C_{x} V \lambda}{A\left(T+\lambda^{-1}\left(e^{-T \lambda}-1\right)\right)}
$$

where:

$C_{x}$ : The radon concentration in the sample.

$V$ : The volume of air in the box

$$
V=\pi r^{2} h=\frac{22}{7} \times(3.6)^{2} \times 5.8=236 \mathrm{~cm}^{3}
$$

$\lambda$ : The dissolution constant of radon gas per day $\left(\frac{0.1812}{\text { day }}\right)$, for each hour it is $\left(\frac{0.00755}{h}\right)$.

$A$ : The surface area of each sample

$$
A=\pi r^{2}=\frac{22}{7} \times(1.8)^{2}=10.17 \mathrm{~cm}^{2}
$$

$T$ : The time of exposure of the detector to the sample which is (50 day) per hour $(1200 \mathrm{~h})$.

4. The annual effective dose for exposure to radon.

The annual effective consumer dose for exposure to radon gas in cosmetics is obtained from the following relationship $[11,19]$ :

$$
A E D_{x}=C_{x} C_{R x} D_{C x}
$$


$C_{r x}$ : The annual amount (consumption) of cosmetic products of various kinds per day $\left(\frac{L}{Y}\right)$.

So annually $\left(0.015 \times 360=5.5 \frac{\mathrm{Kg}}{\text { year }}\right)$.

$C_{x}$ : Radon concentration $\left(\frac{B q}{L^{-1}}\right)$.

$D_{c x}$ : The dose conversion factor for radon $\left(5 \times 10^{-9} \frac{S v}{B q}\right)$.

\subsection{Components of samples}

In this section, the components of samples under consideration are displayed with details:

1. The first sample (A1): Sample name (Clean and Clear) face wash (Clean and Clear) of French origin. It contains the basic ingredients of emulsifiers, thickeners and aromatic materials in addition to water, colorants and preservatives. The anti-acne foaming face wash is used to cleanse the skin with salicylic acid, a form of phenolic acid that is a transparent liquid that is generated or extracted from plants as well as natural aloe Vera extracts.

2. The second sample (A2): The name of the sample is Charcoal Facial SCRuB Cream (American origin) Charcoal face scrub cream. It is one of the natural preparations that consists of condensed materials and preservatives in addition to colorants as well as water and emollients. In general, it consists of activated charcoal Similar to regular coal and tenorite clay.

3. The third sample (A3): The name of the sample is a basic medicinal cream that treats defects (HEALTHY ELIXIR) origin (PRC). All foundations are made with three main groups of ingredients, which are moisturizers, colorants, and fillers. The powder foundation does not contain water Where moisturizing foundations are made of water, oil or wax, with the addition of pigments such as iron oxide to match the color of the base, a color that contains SPF of $20 \%$.

4. The fourth sample (A4): The sample name is "BB" cinematic cream (Seven girl) of German origin. This cream contains BB cream. It contains zinc oxide and titanium oxide, which are one of the components of sunscreen in addition to containing vitamin $\mathrm{E}, \mathrm{A}$, and $\mathrm{C}$, as well as moisturizers glycerin, melosinic and mica component. Also, it contains dimethicone, glycerol, stearic acid, aster siloxane, methylsiloxane, isopropyl myristate, white cosmetic oil, ethyl Paraben, Propyl Ester as well as Nacl, 7H2O, MgSo4, Propylene Glycol.

5. The fifth sample (A5): The name of the sample is a toner with rose water (Water bull) of Origin Jordan. It is used to purify, lighten, tighten, tighten the skin and clear its clarity. It is also used to help protect the skin from harmful sun rays. It is characterized by containing nourishing vitamins as well as vitamin C, which gives vital skin as the main components of a face toner are moisturizers, emulsifiers and aromatic materials, as well as water, detergents and preservatives. Among the most important acids that are used in the manufacture of salicylic acid, glycolic acid, melaleuca oil, hexylin glycol and retinol.

6. The sixth sample (A6): The name of the sample is "bb" (5 in 1). It gives the rich bb cream and provitamin B5 and gives the skin a flawless, healthy and instantly beautiful appearance. A product that is gentle on the skin is identical to the skin and does not cause any gluteal reactions. The most important components of this sample are aqua, glycerol, triisetrine isopropic stearate, talc, cetostearyl alcohol, hydrogenated cocoa glyceroate, or ketocrylene, mole bruga ndoyle, barky butterbutidospermum, glycerol stearate, sodium citrate, xanthan gum, trisodium benzyl alcohol and some aromatic compounds in addition to reagents and preservatives, as well as colorants. Figure 3 shows the samples of cosmetics used in the study.

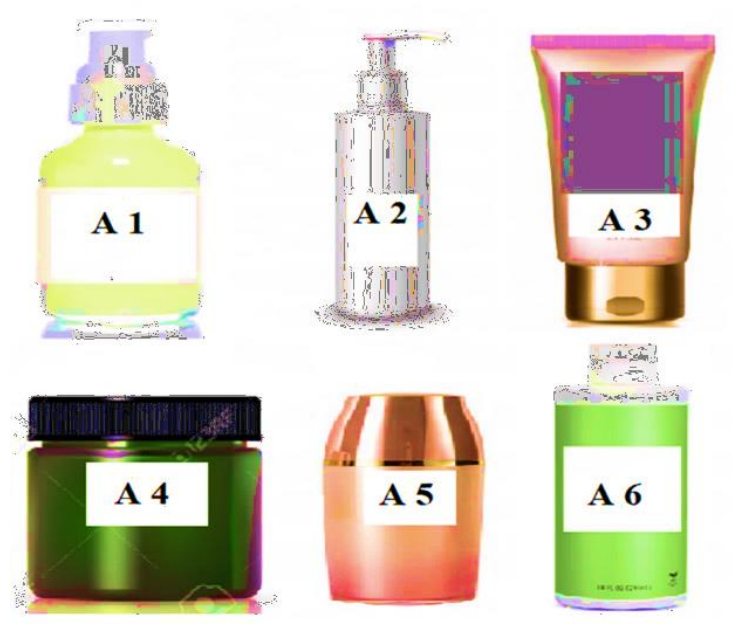

Figure 3. The samples of cosmetics used in the study

\section{RESULTS AND DISCUSSION}

Exposure to radon gas is one of the contemporary problems that have emerged with the development of radiation and nuclear sciences, especially from its environmental side and related health damages. Therefore, it is necessary to study its focus in the most commonly used materials that are in direct contact with people's lives, and among these materials are cosmetics, especially those that are used in abundance and containing a wide range of chemical compounds and organic alcohols.

Table 1 shows the samples under consideration and their rate of effects while Table 2 displays the measurement outcomes of the tested samples. The findings of this analysis show that there is a difference between the radon concentrations in each sample. on the other words, the results differed between the maximum and the minimum.

According to Table 2, Figure 4, and Figure 5, the radon concentrations differ from one sample to another in the studied samples, where the highest value of radon gas was in the sample (A2). This indicates that the chemical composition of this sample has the largest role in the high concentration of radon gas compared to other samples. As this sample consists of activated charcoal similar to ordinary coal and tenonite clay, and because of this composition, the concentrations were high in this sample, as well as the rate of evaporation of radon gas is high in this sample in addition to the annual effective dose is high compared to other samples. Therefore, sample (A2) recorded the highest value of $0.0795\left(\mathrm{~Bq} / \mathrm{m}^{3}\right)$ and 13.062 $\left(\mathrm{Bq} / \mathrm{m}^{3}\right)$ for radon concentration in air and the radon concentration in the Charcoal face sanding, respectively. 
Table 1. The samples and their rate of effects

\begin{tabular}{ccccc}
\hline No. & $\begin{array}{c}\text { The code of the } \\
\text { sample }\end{array}$ & $\begin{array}{c}\text { The local name } \\
\text { of the sample }\end{array}$ & $\begin{array}{c}\text { The trade names } \\
\text { of the sample }\end{array}$ & $\begin{array}{c}\text { Average number of antiquities } \\
\text { on the sample (The number of antiquities } \\
\text { was calculated three times) }\end{array}$ \\
\hline $\mathbf{1}$ & A1 & Face wash & Clear had Clear & $11+13+10=11.5 \pm 1.5$ \\
\hline $\mathbf{2}$ & A2 & $\begin{array}{c}\text { Charcoal face } \\
\text { sanding }\end{array}$ & Charcoal Facial SCRuB & $16+17+14=15.66 \pm 1.66$ \\
\hline $\mathbf{3}$ & A3 & $\begin{array}{c}\text { Medical basis } \\
\text { for hiding defects }\end{array}$ & HEALTY ELIXIR & $9+10+8=9 \pm 1$ \\
\hline $\mathbf{4}$ & A4 & Cinema Foundatin BB & Seven girls & $14+15+17=15.33$ \\
\hline $\mathbf{5}$ & A5 & Toner for water flower & bb (5 inl) & $7+9+8=8 \pm 1$ \\
\hline $\mathbf{6}$ & A6 & Technical basis & & $7+8=7 \pm 1$ \\
\hline
\end{tabular}

Table 2. The trace density of alpha particles, the radon concentration, the rate of radon gas and the average annual effective dose

\begin{tabular}{ccccc}
\hline Sample & $\begin{array}{c}\boldsymbol{\rho}_{\boldsymbol{x}} \\
=\left(\frac{\text { tracks }}{\boldsymbol{m m}^{\mathbf{2}}}\right)\end{array}$ & $\begin{array}{c}\boldsymbol{C}_{\boldsymbol{x}} \\
=\left(\frac{\boldsymbol{B q}}{\boldsymbol{m}^{\mathbf{3}}}\right)\end{array}$ & $\begin{array}{c}\text { RER } \\
\boldsymbol{E}_{\boldsymbol{e x h}} \\
=\frac{\boldsymbol{q}}{\boldsymbol{m}^{\mathbf{2}} \boldsymbol{h}} \boldsymbol{\mu B}\end{array}$ & $\begin{array}{c}\text { Annual } \\
\text { effective } \\
\text { dose }\end{array}$ \\
\hline $\mathrm{A} 1$ & 7.55 & 0.0575 & 9.455 & 15.8 \\
\hline $\mathrm{A} 2$ & 10.44 & 0.0795 & 13.062 & 21.8 \\
\hline $\mathrm{A} 3$ & 6 & 0.0457 & 7.509 & 12.5 \\
\hline A4 & 10.22 & 0.0778 & 12.781 & 21.3 \\
\hline A5 & 5.33 & 0.0406 & 6.671 & 11.1 \\
\hline A6 & 4.66 & 0.0355 & 5.833 & 9.8 \\
\hline
\end{tabular}

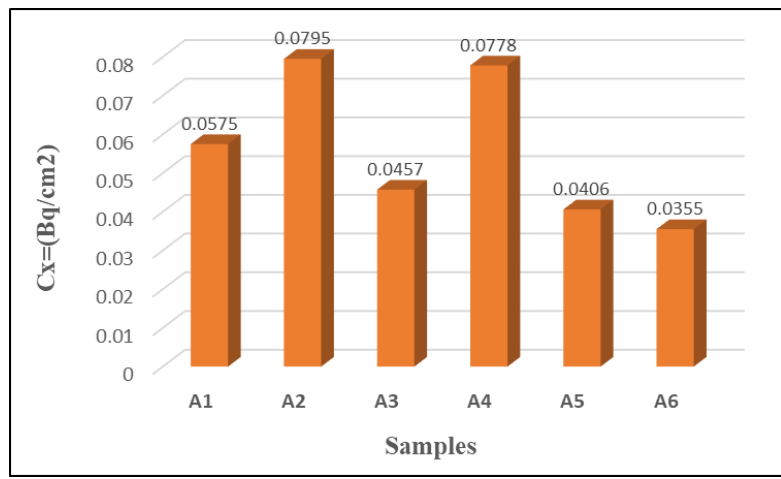

Figure 4. Concentration of radon in the air of cosmetic samples

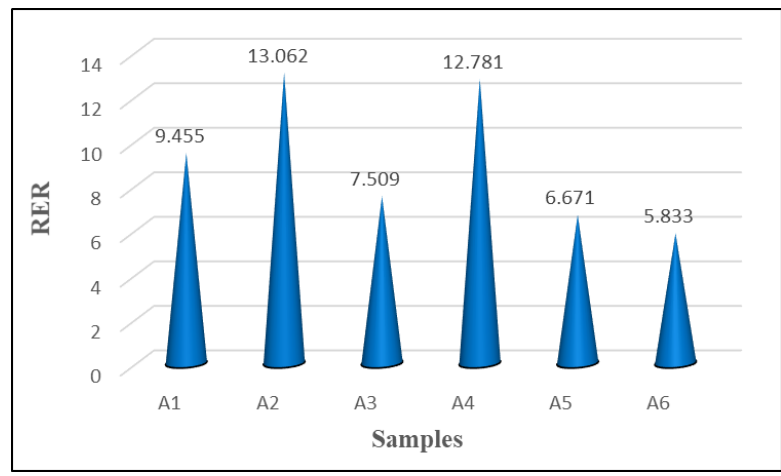

Figure 5. Radon gas concentration for cosmetic samples

Sample (A4) scored second in terms of concentration of radon gas. This rise can be explained by its chemical composition, which consists of zinc oxide and titanium oxide, which are one of the components of sunscreens in addition to its containment of vitamins E, A, C. In addition, glycerin moisturizers, melons and mica element in addition to dimethicone, glycerol Stearic acid cyclic siloxane ester, methylsiloxane, isopropyl myristate white grade cosmetic oil, ethyl parable, propyl ester as well as $\mathrm{Nacl}, 7 \mathrm{H} 2 \mathrm{O}, \mathrm{MgSo} 4$, propylene glycol. In other words, sample A4 recorded a radon concentration in air $\left(0.0778 \mathrm{~Bq} / \mathrm{m}^{3}\right)$ that correspond to the value for the radon concentration in the Cinema Foundation BB sample, which equal $\left(12.781 \mathrm{~Bq} / \mathrm{m}^{3}\right)$.

Looking to the samples A3 that is recorded the third scored after A2 and A4. The results uncovered that the radon concentration in this sample, i.e., Face wash, is $9.455 \mathrm{~Bq} / \mathrm{m}^{3}$ which is corresponding $0.0575 \mathrm{~Bq} / \mathrm{m}^{3}$ of radon concentration in air.

The third and fifth samples showed a moderate tendency in radon concentration, which recorded 0.0457 and $0.0406 \mathrm{~Bq} / \mathrm{m}^{3}$, respectively. The reason for this is due to the chemical composition of the two samples, as previously mentioned.

Here it is necessary to compare the results obtained with international measurements that represent the limits of the permissible dose of radon gas in water. Therefore, it is very large. For example, the World Health Organization specified (0.3996 Becquerel per liter), while the International Agency for Radiation Protection set the permissible values $(0.5994$ Becquerel per liter). on the other hand, when comparing the results with the value (11 Becquerels per liter) recommended by the US Environmental Protection Agency (2000), it is less than the permissible value. Accordingly, the concentrations of all the study samples are within the natural level of radon gas, but the danger lies in the frequent uses of these materials as well as the use of more than one type for long periods.

\section{CONCLUSIONS}

There are differences in the results obtained between relatively high and very low, and this is due to the nature of the composition of the materials used in the composition of the samples. The rate of radon gas concentration in the A2 sample is high compared to the rest of the study samples and this is due to its chemical composition. The radon concentration in the study samples is within the permissible limits according to some international organizations and agencies. The average annual effective dose of the samples is within the permissible limits, and since the dose rate is low in the samples, the effects are known at these doses. However, if the dose rate exceeds the permissible limits, this means that the doses are high, and when tissues and organs are exposed to high doses, a large number of their cells die, and the process of rebuilding new cells cannot replace the missing fraction of his cells. Thus, leads a great shortage in the cells of an organ or tissue, which leads to the loss of an organ or tissue of its function. If the tissue or organ is one of the vital parts for the continuation of the organism's life, death is the inevitable result. 


\section{REFERENCES}

[1] Shuryak, I. (2019). Review of microbial resistance to chronic ionizing radiation exposure under environmental conditions. Journal of Environmental Radioactivity, 196: 50-63. https://doi.org/10.1016/j.jenvrad.2018.10.012

[2] Belli, M., Indovina, L. (2020). The response of living organisms to low radiation environment and its implications in radiation protection. Frontiers in Public Health, 8. https://doi.org/10.3389/fpubh.2020.601711

[3] Polgár, C., Ott, O.J., Hildebrandt, G., Kauer -Dorner, D., Knauerhase, H., Major, T., Radiotherapy, S. (2017). Late side-effects and cosmetic results of accelerated partial breast irradiation with interstitial brachytherapy versus whole-breast irradiation afterbreast-conserving surgery for low-risk invasive and in- situ carcinoma of the female breast: 5-year results of a randomised, controlled, phase 3 trial. The Lancet Oncology, 18(2): 259-268. https://doi.org/10.1016/S1470-2045(17)30011-6

[4] Kadhim, M., Salomaa, S., Wright, E., Hildebrandt, G., Belyakov, O.V., Prise, K.M., Little, M.P. (2013). Nontargeted effects of ionising radiation-implications for low dose risk. Mutation Research/Reviews in Mutation Research, 752(2): 84-98. https://doi.org/10.1016/j.mrrev.2012.12.001

[5] Bua, L., Tibaldi, E., Falcioni, L., Lauriola, M., De Angelis, L., Gnudi, F., Manservigi, M., Manservisi, F., Manzoli, I., Menghetti, I., Montella, R., Panzacchi, S., Sgargi, D., Strollo, V., Vornoli, A., Mandrioli, D., Belpoggi, F. (2018). Results of lifespan exposure to continuous and intermittent extremely low frequency electromagnetic fields (ELFEMF) administered alone to Sprague Dawley rats. Environmental Research, 164: 271-279. https://doi.org/10.1016/j.envres.2018.02.036

[6] Krewski, D., Lubin, J.H., Zielinski, J.M., Alavanja, M., Catalan, V.S., William Field, R., Klotz, J.B., Létourneau, E.G., Lynch, C.F., Lyon, J.L., Sandler, D.P., Schoenberg, J.B., Steck, D.J., Stolwijk, J.A., Weinberg, C., Wilcox, H.B. (2006). A combined analysis of North American case- control studies of residential radon and lung cancer. Journal of Toxicology and Environmental Health, Part A, 69(7-8):

533-597. https://doi.org/10.1080/15287390500260945

[7] Cho, B.W., Choo, C.O. (2019). Geochemical behavior of uranium and radon in groundwater of Jurassic granite area, Icheon, Middle Korea. Water, 11(6): 1278. https://doi.org/10.3390/w11061278

[8] Kulal1, F., Akkurt, İ., Özgür, N., Sezer, M. (2018). The correlation of the seismic activities and radon concentration in soil gas. Arabian Journal of Geosciences, 11(16): 1-4. https://doi.org/10.1007/s12517-018-3743-8

[9] Bersimbaev, R.I., Bulgakova, O. (2015). The health effects of radon and uranium on the population of Kazakhstan. Genes and Environment, 37(1): 1-10. https://doi.org/10.1186/s41021-015-0019-3

[10] Seoud, M.S. (2018). Health risk assessment of radon-222 concentration in some imported cosmetics by using nuclear track detector (CR-39). SciFed Journal of Nuclear $\quad$ Science, 2(2) https://www.researchgate.net/profile/Mohamed-

Seoud/publication/334807623_Health_Risk_Assessmen t_of_Radon-
222 Concentration in Some Imported Cosmetics by Using_Nuclear_Track_Detector_CR-

39/links/5d7a7a0e92851c87c377 ed84/Health-Risk-

Assessment-of-Radon-222-Concentration-in-SomeImported-Cosmetics-by-Using-Nuclear-Track-DetectorCR-39.pdf.

[11] Salman, E.F., Abass, A.H., Almayahi, B.A. (2019). Effects of Radon Gas on Human Health in some of Cosmetics. La Prensa Medica Argentina, 105: 1-3. https://www.researchgate.net/profile/Entesser-

Salman/publication/343754371_Effects_of_Radon_Gas _on_Human_Health_in_some_of_Cosmetics/links/6039 e8a792851c4ed59d8564/Effects-of-Radon-Gas-onHuman-Health-in-some-of-Cosmetics.pdf.

[12] Ali, A.H., Mh, A.K., Hassan, H.I. (2014). Determination of the background radiation level in Mosul university campus using multiple technologies. Rafidain Journal of Science, 25(5): 86-100. https://doi.org/10.33899/rjs.2014.131371

[13] Reimann, C., Hall, G.E.M., Siewers, U., Bjorvatn, K., Morland, G., Skarphagen, H., Strand, T. (1996). Radon, fluoride and 62 elements as determined by ICP - MS in 145 Norwegian hard rock groundwater samples. Science of the Total Environment, 192(1): 1-19. https://doi.org/10.1016/0048-9697(96)05272-2

[14] Fiume, M.M., Boyer, I., Bergfeld, W.F., Belsito, D.V., Hill, R.A., Klaassen, C.D., Liebler, D.C., Marks, J.G., Shank, R.C., Slaga, T.J., Snyder, P.W., Andersen, F.A. (2015). Safety assessment of talc as used in cosmetics. International Journal of Toxicology, 34(1_suppl): 66S129S. https://doi.org/10.1177/1091581815586797

[15] Papadopoulos, A., Giouri, K., Tzamos, E., Filippidis, A., Stoulos, S. (2014). Natural radioactivity and trace element composition of natural clays used as cosmetic products in the Greek market. Clay Minerals, 49(1): 5362. https://doi.org/10.1180/claymin.2014.049.1.05

[16] Milena-Pérez, A., Martínez-Martínez, B.R., Álvarez, E., Expósito-Suárez, V.M., Piñero-García, F., Ferro-García, M.A. (2019). Natural radium isotopes present in some cosmetic products: Determination of activity concentration and dose estimation. Radiation Protection Dosimetry, 187(1): 28-33. https://doi.org/10.1093/rpd/ncz133

[17] Al-Alawy, I.T., Hasan, A.A. (2018). Radon concentration and dose assessment in well watersamples from karbala governorate of Iraq. In Journal of Physics: Conference $\quad$ Series, $1003(1): \quad 012117$. https://doi.org/10.1088/1742-6596/1003/1/012117

[18] Mathloom, A.R., Alkhafaji, M.H., Al-Hachami, A.A. (2021). The study of determining the levels of radon gas concentrations (soil, water and plants) in the areas exposed to military operations in Suq Al-Shuyoukh district, south of Thi-Qar province, Iraq. In Journal of Physics: Conference Series, 1804(1): 012146. https://doi.org/10.1088/1742-6596/1804/1/012146

[19] Al-Alawy, I.T., Fadhil, H.R. (2015). Measurements of radon concentrations and dose assessments in Physics Department-Science College-Al-Mustansiriyah University, Baghdad, Iraq. International Letters of Chemistry, Physics and Astronomy, 60: 83-93. https://doi.org/10.18052/www.scipress.com/ILCPA.60. 83 